\title{
Kallikrein-kininogen system activation and bradykinin (B2) receptors in indomethacin induced enterocolitis in genetically susceptible Lewis rats
}

\author{
A Stadnicki, R B Sartor, R Janardham, I Stadnicka, A A Adam, C Blais Jr, R W Colman
}

\begin{abstract}
Background-The plasma kallikrein-kinin (K-K) system is activated in acute and chronic relapsing intestinal inflammation induced in Lewis rats by intramural injection of exogenous bacterial components. Aims-To determine whether this effect is model specific, K-K system activation was investigated in a modified indomethacin induced enterocolitis model, as well as bradykinin 2 (B2) receptor distribution in the normal and acutely inflamed intestine. Methods-Lewis rats injected with daily sublethal doses of indomethacin for two days developed acute (two days) and chronic (14 days) intestinal inflammation. Plasma prekallikrein (amidolytic), high molecular weight kininogen (HK, coagulant) and cleavage of HK (western blot)
\end{abstract} were assayed to detect $K-K$ activation.

Results-Liver and spleen weights were significantly higher, and body weights and haematocrit values were significantly lower in the indomethacin group than in the control group. During both acute and chronic phases, rats displayed $\mathrm{K}-\mathrm{K}$ system activation manifested by a significant decrease in plasma prekallikrein and HK functional levels, and by HK cleavage. Plasma T kininogen (a major acute phase protein) was significantly elevated. B2 receptors were identified in both normal and inflammatory intestine with more prominent specific immunohistochemical staining in the acutely inflamed tissue.

Conclusions-K-K system activation occurs in association with both acute and chronic phases of intestinal injury, regardless of the triggering agent, suggesting that activation of this system is integrally involved in intestinal inflammation in genetically susceptible hosts. Localisation of $B 2$ receptors across intestinal layers provides a structural basis for the kinin function in the intestine.

(Gut 1998;43:365-374)

Keywords: plasma kallikrein; kininogen; bradykinin 2 receptor; enterocolitis; indomethacin; proteoglycan-polysaccharide

Idiopathic inflammatory bowel diseases (IBD), including Crohn's disease and ulcerative colitis, are complex disorders with multiple pathogenic factors including cellular and humoral inflammatory cascades, genetic susceptibility, and environmental influences. ${ }^{1}$ The aetiopathogenesis of IBD is incompletely understood; however, progress is being made owing to the development of improved animal models of enterocolitis. ${ }^{2}$ Enteric bacteria have long been postulated to play an important role by initiating or perpetuating intestinal inflammation in the genetically susceptible host. ${ }^{1}$ Peptidoglycan-polysaccharide (PG-PS), a bacterial cell wall polymer common to most bacteria, is used as an inducer of intestinal and extraintestinal inflammation in one of the rat enterocolitis models that we employ. ${ }^{3}$ The inflammatory response initiated by PG-PS is similar to that present in human IBD in that it is mediated by leucocyte activation with liberation of cytokines and eicosanoids, and activation of plasma proteolytic pathways. ${ }^{14} \mathrm{Re}-$ cently, we have shown that activation of the kallikrein-kinin (contact) system occurs in acute $^{5}$ and chronic relapsing ${ }^{3}$ intestinal inflammation induced in Lewis rats by intramural intestinal injection of PG-PS derived from group A streptococci. This model requires a specific genetic background as only susceptible Lewis rats (but not resistant Buffalo rats) develop chronic, relapsing, granulomatous intestinal and systemic inflammation with associated activation of the kallikrein-kinin system. $^{3}$

The plasma contact system comprises factor XII, prekallikrein (PK), and factor XI (FXI), which are zymogens of proteases, and high molecular weight kininogen (HK), which serves as the cofactor of contact activation. ${ }^{6}$ The consequences of activation of this system include the conversion of PK to the proteolytic enzyme, kallikrein, which releases bradykinin from $\mathrm{HK}$, and activation of FXI to FXIa, which may contribute to the intrinsic coagulation pathway. ${ }^{6}$ Kallikrein is a chemoattractant for neutrophils, which it stimulates to aggregate ${ }^{7}$ and release elastase ${ }^{8}$ and superoxides. ${ }^{9}$ Plasma kallikrein cleaves $\mathrm{HK}$ in a three step pattern. In humans, the first cleavage yields a heavy chain of HK $(64 \mathrm{kDa})$ and a light chain of HK (56 $\mathrm{kDa}$ ) on a reduced sodium dodecyl sulphate (SDS) gel. The second cleavage yields bradykinin. The third cleavage results in a stable kinin free protein (64 $\mathrm{kDa}$ and $45 \mathrm{kDa}$ chains), and additional small peptides. Bradykinin is a potent inflammatory mediator which expresses a biological effect by activating constitutive B2 receptors, whereas des-Arg9 bradykinin, its active metabolite, acts on B1 receptors, 
induced by inflammatory cytokines, on endothelial cells, smooth muscle cells, epithelial cells, and fibroblasts. ${ }^{10}$ In the intestine, bradykinin acting through $\mathrm{B} 2$ receptors has been implicated in ion transport, pain induction, and motility. ${ }^{11}$ However, B2 receptor distribution in the intestinal layers has not been described.

Activation of the kallikrein-kinin system is directly involved in the pathogenesis of PG-PS induced intestinal injury. We have documented that a specific plasma kallikrein inhibitor attenuates acute ${ }^{5}$ and chronic ${ }^{12}$ phases of intestinal inflammation. Activation of the kallikreinkinin system has been implicated in various other experimental inflammatory ${ }^{13}$ and human disease ${ }^{15}$ states in which exogenous bacterial products such as endotoxin (lipopolysaccharide, LPS) seem to be aetiologically important. The similarity of biological responses to LPS and PG-PS coincides with the ability of both bacterial products to induce similar cytokines and mediators. ${ }^{4}$ However, it is not clear whether activation of the kallikreinkinin pathway is limited to enterocolitis models triggered by exogenous bacterial polymers or whether it could be generalised to other experimental intestinal inflammatory conditions and, ultimately, to human IBD. Therefore, we investigated whether the kallikreinkinin system is activated in an enterocolitis model induced by a chemical substance, indomethacin.

A recent modification of the indomethacin induced enterocolitis model ${ }^{16}$ to induce chronic mid small intestinal inflammation in genetically susceptible Lewis rats has been described in a preliminary communication. In the current study, we used this reproducible model to quantify the inflammatory response measuring macroscopic, histological, and biochemical markers of intestinal inflammation and evaluated extraintestinal complications. We measured $\mathrm{T}$ kininogen, the major type 2 acute phase protein in the rat, which increases strikingly in inflammatory reactions. ${ }^{17}$ To assess the participation of the kallikrein-kinin system, we measured the plasma contact proteins and analysed the HK cleavage pattern qualitatively. In order to visualise the B2 receptors which mediate the proinflammatory effect of the kinins, we employed immunohistochemistry with antibodies to specific amino acid sequences (peptides) in the receptor. The results indicate that activation of the kallikrein-kinin system is not limited to intestinal inflammation induced by exogenous bacterial products. The present study also indicates that kinin may mediate intestinal inflammation through B2 receptors which we visualised for the first time in the intestinal layers.

\section{Methods}

MATERIALS

The chromogenic substrates S-2302 (prekallikrein/kallikrein), S-2366 (factor XI), and plasma prekallikrein activator were purchased from Pharmacia (Franklin, Ohio). Microplates (no. 3075) were obtained from
Falcon Plastic (Mt Laurel, New Jersey). Indomethacin was purchased from Sigma (St Louis, Missouri).

EXPERIMENTAL PROTOCOL

A total of 36 female inbred Lewis rats (Charles River Laboratories, Raleigh, New Carolina), mean weight $180 \mathrm{~g}$, was used. Rats were housed in pathogen free conditions and fed standard rat chow and water. The experiment was performed to evaluate both the acute phase (two day) and chronic phase (14 day) of inflammation. Rats were separated into two groups. The treated animals received two subcutaneous injections of indomethacin (7.5 $\mathrm{mg} / \mathrm{kg}$ in $0.3 \mathrm{ml}$ buffer daily at 24 hour intervals). To prepare this buffer, indomethacin was first dissolved in absolute ethanol (50 $\mathrm{mg} / \mathrm{ml}$ ) and then diluted fivefold with $0.1 \mathrm{M}$ $\mathrm{NaHCO}_{3}, \mathrm{pH} 7.0$, filtered, and diluted in 0.1 $\mathrm{M} \mathrm{NaHCO}$ to final concentration. The control animals were injected subcutaneously twice with $20 \%$ ethanol in $0.1 \mathrm{M} \mathrm{NaHCO}_{3}$. Animals were killed by inhalation of $100 \% \mathrm{CO}_{2}$ (eight controls and 13 experimental in the acute phase; and seven controls and eight experimental in the chronic phase). Cardiac blood was aspirated from the right ventricle by an 18 gauge needle into a syringe containing $3.8 \%$ sodium citrate $(9 / 1, \mathrm{vol} / \mathrm{vol})$ for coagulation assays and $20 \mathrm{mM}$ EDTA for haematological measurements. In addition, in some rats blood was anticoagulated with a mixture of protease inhibitors containing polybrene $(400$ $\mu \mathrm{g} / \mathrm{ml})$, EDTA (20 mM), benzamidine (100 $\mathrm{mM})$, and soybean trypsin inhibitor $(2 \mathrm{mg} / \mathrm{ml})$ for western blot analysis. Citrated blood was twice centrifuged at $23^{\circ} \mathrm{C}$ to obtain the plasma and then stored at $-70^{\circ} \mathrm{C}$.

ASSESSMENT OF INTESTINAL INFLAMMATION At necropsy, intestinal inflammation was quantitated by gross examination by an observer blinded to the identity of the rat as experimental or control, and tissue was collected for histological evaluation and biochemical analysis. A gross gut score was calculated using the sum of 0-4 determinations of intestinal wall thickening, adhesions, and mesenteric contraction. This score is a minor modification of the method previously validated in the PG-PS enterocolitis model, ${ }^{3}$ removing only the determination for serosal nodules, which do not occur following indomethacin injection. The maximum gross score was 12 . The most involved $10 \mathrm{~cm}$ segment of small bowel was then excised and opened longitudinally, and mucosal ulcers were counted in the small bowel. We also measured the percentage of the mucosal surface area which was ulcerated in this $10 \mathrm{~cm}$ segment. The tissue was divided in half and prepared for histology and tissue interleukin $1 \beta$ (IL-1 $\beta$ ) determinations. Tissue was homogenised in $20 \mathrm{mM}$ phosphate buffer ( $\mathrm{pH}$ 7.4) and centrifuged at $6000 \mathrm{~g}$ for $20 \mathrm{~min}$ utes at $4^{\circ} \mathrm{C}$. The supernatant was assayed for IL-1 $\beta$ using a previously described enzyme linked immunosorbent assay (ELISA) provided and developed by Dr S Poole, National Institute of Biostandards and Controls Labora- 

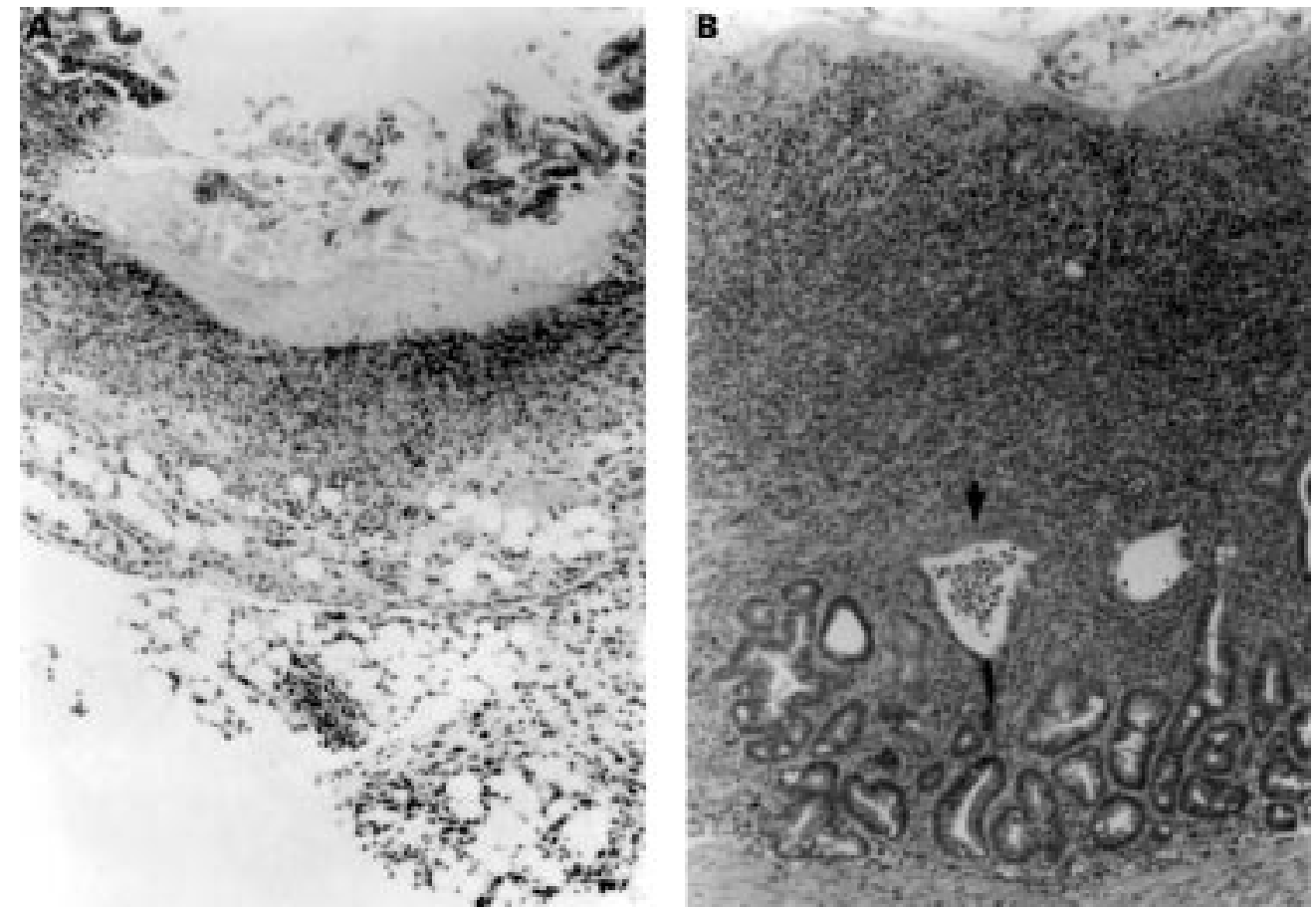

Figure 1 Histological evidence of enteritis induced by indomethacin in female Lewis rats. (A) At day 2, after subcutaneous injection of $7.5 \mathrm{mg} / \mathrm{kg}$ indomethacin for two days, a large ulcer with relatively bland necrosis of the entire mucosa is seen with severe serosal and mesenteric inflammation with neutrophils and macrophages (original magnification $\times 100$ ). (B) At day 14, there is an extensive ulcer with an active mucosal exudate. A crypt abscess is visible (arrow) and glandular dysplasia with depletion of goblet cells. Transmural inflammation with thickening of the submucosa is evident. The infiltrate consists of both mononuclear cells and neutrophils with fibroblast proliferation and smooth muscle hypertrophy. Collagen indicative of early fibrosis is present (original magnification $\times 100$ ).

tory, Herefordshire, UK. ${ }^{18}$ Results were expressed as units of IL-1 $\beta$ activity per gram wet tissue weight. A blinded histological score was calculated as follows on tissues fixed in $10 \%$ buffered formalin and stained with haematoxylin and eosin. For each of four segments of small intestine scored, an acute histology score of $0-4+$ was given as follows: 0 , no injury; $1+$, infiltration of scattered neutrophils; $2+$, infiltration of numerous neutrophils, no ulceration; $3+$, superficial ulceration with preservation of the submucosa and muscle layers; 4+, transmural necrosis with abscess. Chronic histological inflammation was scored as: $1+$, focal scattered mononuclear cell infiltration; 2+, infiltration of numerous mononuclear cells; $3+$, thickening of submucosa with confluent mono- nuclear cells adjacent to ulcer; $4+$, distortion of architecture with dramatic thickening of cell layers. The acute and chronic score of each segment was added, and a mean histological score (maximum score 8 , minimum score 0 ) calculated from all segments studied. The gross gut score and the mean histological score are tabulated separately for the acute phase of enterocolitis (day 2) and the chronic phase of enterocolitis (day 14).

DETERMINATION OF SYSTEMIC COMPLICATIONS Rats were weighed just before each indomethacin injection and at days 2 and 14. At necropsy, liver and spleen were excised and weighed and results were expressed as organ
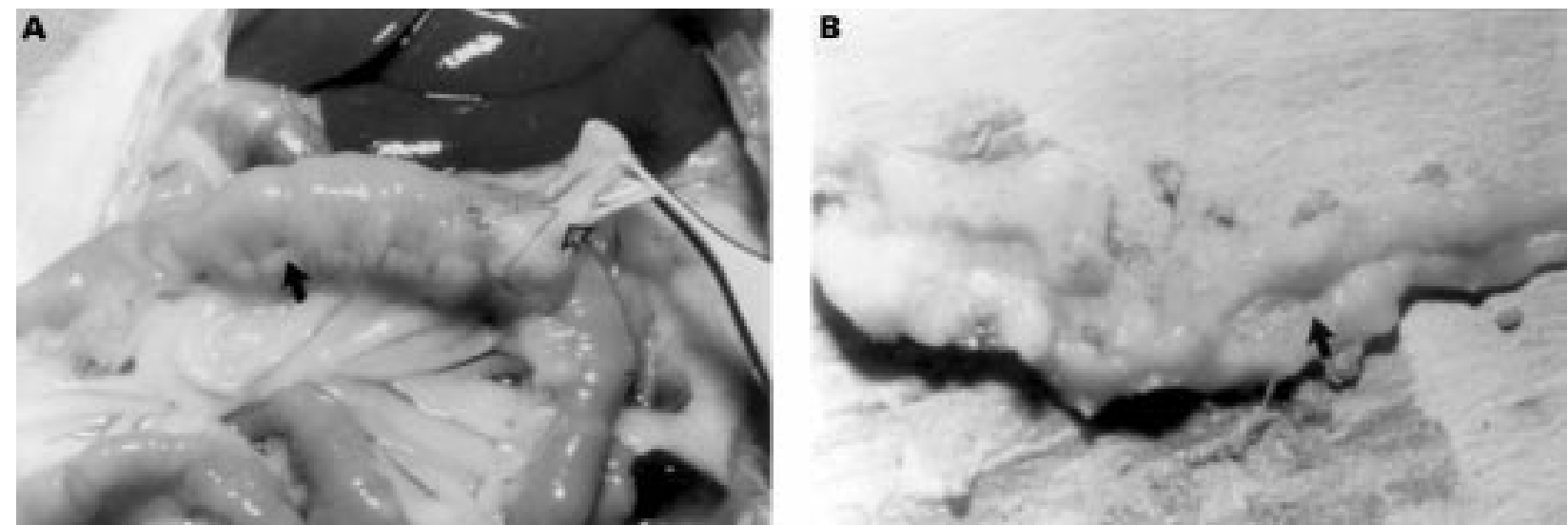

Figure 2 Gross appearance of intestinal inflammation in indomethacin treated Lewis rats. (A) Thickening of the bowel wall with creeping mesenteric fat (closed arrow) and adhesions (open arrow) is present at day 14 after injection of indomethacin on days 0 and 1 . (B) Longitudinal ulcers (arrow) on the mesenteric border are seen in the mid small bowel at day 14. 
Table 1 Intestinal inflammation in Lewis rats two and 14 days after subcutaneous injection with buffer or indomethacin

\begin{tabular}{|c|c|c|c|c|c|c|}
\hline & No of rats & Gross gut score & $\begin{array}{l}\text { No of ulcers in small } \\
\text { bowel }\end{array}$ & $\begin{array}{l}\text { Percentage of surface } \\
\text { area ulcerated }\end{array}$ & $\begin{array}{l}\text { Histological } \\
\text { inflammatory score }\end{array}$ & $I L-1 \beta$ (pg/mg tissue) \\
\hline \multicolumn{7}{|c|}{ Acute phase ( 2 days) } \\
\hline Indomethacin & 13 & $4.1(0.58)^{\star \star \star}$ & $14.3(1.4)^{\star \star \star}$ & $26.4(6)^{\star \star}$ & $3.7(0.3)^{\star \star \star}$ & $21.3(5.0)^{\star \star}$ \\
\hline Control & 8 & 0 & 0 & 0 & $0.1(0.03) \dagger$ & $5.3(1.9) \S$ \\
\hline \multicolumn{7}{|c|}{ Chronic phase (14 days) } \\
\hline Indomethacin & 8 & $10.3(1.0)^{\star \star \star}$ & $7.0(1.2)^{\star \star \star}$ & $36(7.7)^{\star \star}$ & $4.5(0.7)^{\star \star \star}$ & $46.2(11.4)$ \\
\hline Control & 7 & 0 & 0 & 0 & $0.2(0.1) \ddagger$ & $0.2(0.03) \ddagger$ \\
\hline
\end{tabular}

Results are expressed as mean (SEM).

${ }^{\star \star} \mathrm{p}<0.01, \star \star \star \mathrm{p} \leqslant 0.001$.

$\dagger$ Performed on six indomethacin and four buffer treated rats; $\ddagger$ performed on five indomethacin and four buffer treated rats; \$performed on six indomethacin and seven buffer treated rats.

weight in $\mathrm{mg} / \mathrm{g}$ body weight. Haematocrit of cardiac blood was determined.

\section{ASSAYS OF CONTACT ACTIVATION}

PK levels were determined by a functional amidolytic assay as described in our laboratory. ${ }^{19}$ Factor XI functional levels were measured as previously described. ${ }^{20} \mathrm{HK}$ coagulant activity was evaluated by our modification $^{521}$ (using total kininogen deficient plasma) of the method originally described by Proctor and Rapaport. ${ }^{22}$ In addition, total protein values in rat plasma were measured using the BCA protein assay (Pierce Laboratories) according to the method described by Bradford. ${ }^{23}$

\section{WESTERN BLOT ANALYSIS OF CLEAVAGE OF RAT} PLASMA HK

IgG was purified from rabbit antiserum against rat $\mathrm{HK}$ obtained from Dr A Adam using a protein A column. ${ }^{24}$ The purified IgG was labelled with biotin according to the method described by Hock et al. ${ }^{25}$ The specificity and sensitivity of these antibodies to $\mathrm{HK}$ were analysed by western blotting (see later), and the antibodies were found to cross react weakly with rat serum albumin and $\mathrm{T}$ kininogen, both of which migrate as $68 \mathrm{kDa}$ proteins. To evaluate $\mathrm{HK}$ activation in vitro, pooled Lewis rat plasma was activated with kaolin (Fisher Scientific) 1 $\mathrm{mg} / \mathrm{ml}$ in buffered saline, in proportion $(9 / 1$, $\mathrm{vol} / \mathrm{vol}$ ) at $23^{\circ} \mathrm{C}^{3}$ After 20 minutes incubation, the aliquots containing $30 \mu \mathrm{g}$ protein of either Lewis rat plasma or the same plasma activated with kaolin were removed for western blot analysis. Similarly, the plasma samples containing $30 \mu \mathrm{g}$ protein of three representative control rats and three indomethacin treated rats were assayed on western blots to detect $\mathrm{HK}$ cleavage. Western blotting was performed as previously described. ${ }^{3}$

DETERMINATION OF T KININOGEN IN RAT PLASMA $T$ kininogen was measured by sandwich ELISA as previously described. ${ }^{3}{ }^{26}$
IMMUNOHISTOCHEMISTRY

Rat intestinal tissues obtained in the acute phase of intestinal inflammation following injection with either indomethacin (experimental group) or buffer (control group) were used. The B2 receptor in intestinal tissue was detected using antipeptide antisera from rabbit (a mixture of AS276 and AS283) to the rat B2 receptor (gift from Dr Werner Muller-Esterl, Mainz, Germany) as a primary antibody, produced and characterised as described previously. ${ }^{27}$ The secondary antibody, antirabbit-IgG-avidin-biotin complex, was then added and was detected using an indirect peroxidase technique (ABC Kit, Vector Laboratories, Burlingame, California).

Rat intestinal tissue was embedded in paraffin wax, cut into $5 \mu \mathrm{m}$ thick sections, and stained with haematoxylin and eosin for light microscopy examination. The tissue sections were then dewaxed, rehydrated in xylene and alcohol, and washed in phosphate buffered saline (PBS). The endogenous peroxidase was blocked by incubation for 30 minutes in $0.3 \%$ hydrogen peroxide in cold methanol. Then sections were incubated with normal goat serum for 30 minutes to reduce non-specific binding. Sections were incubated with either antipeptide antibodies to rat $\mathrm{B} 2$ receptor $(2.5-10 \mathrm{mg} / \mathrm{ml})$, or normal rabbit IgG at the same concentration as a control for one hour. Antigen-antibody complexes were detected with an antirabbit-IgG-biotinylated avidinhorseradish peroxidase complex according to the manufacturer's instructions. Finally, the sections were stained with 3,3'diaminobenzidine substrate and then counterstained with Mayer's haematoxylin (Sigma).

\section{STATISTICAL ANALYSIS}

A group of female Lewis rats $(n=10)$ that received neither buffer nor indomethacin was used to normalise the contact system data from the control and indomethacin treated groups. The unpaired two tailed Student's $t$ test $^{28}$ was

Table 2 Body, liver and spleen weights and haematocrit in Lewis rats during the acute and chronic phases of indomethacin induced inflammation

\begin{tabular}{llllll}
\hline & No of rats & Body weight $(g)$ & $\begin{array}{l}\text { Liver weight } \\
(\text { mg/g body weight })\end{array}$ & $\begin{array}{l}\text { Spleen weight } \\
(\mathrm{mg} / \mathrm{g} \text { body weight) }\end{array}$ & Haematocrit (\%) \\
\hline $\begin{array}{l}\text { Acute phase (2 days) } \\
\text { Indomethacin }\end{array}$ & 13 & $172(3.2)^{\star \star}$ & $43.3(1.4)^{\star \star}$ & $3.2(0.2)^{\star \star}$ & $33(1.6)^{\star \star \star}$ \\
$\begin{array}{l}\text { Control } \\
\begin{array}{l}\text { Chronic phase (14 days) } \\
\text { Indomethacin }\end{array}\end{array}$ & 8 & $187(3.2)$ & $38.8(0.5)$ & $2.4(0.1)$ & $47(0.9)$ \\
Control & 8 & $155(4)^{\star \star \star}$ & $59(1.8)^{\star \star \star}$ & $8.0(1.0)^{\star \star}$ & $35(2.8)^{\star \star \star}$ \\
\hline
\end{tabular}

Results are expressed as mean (SEM).

${ }_{\star \star \star} \mathrm{p}<0.01,{ }^{\star \star \star} \mathrm{p} \leqslant 0.001$. 

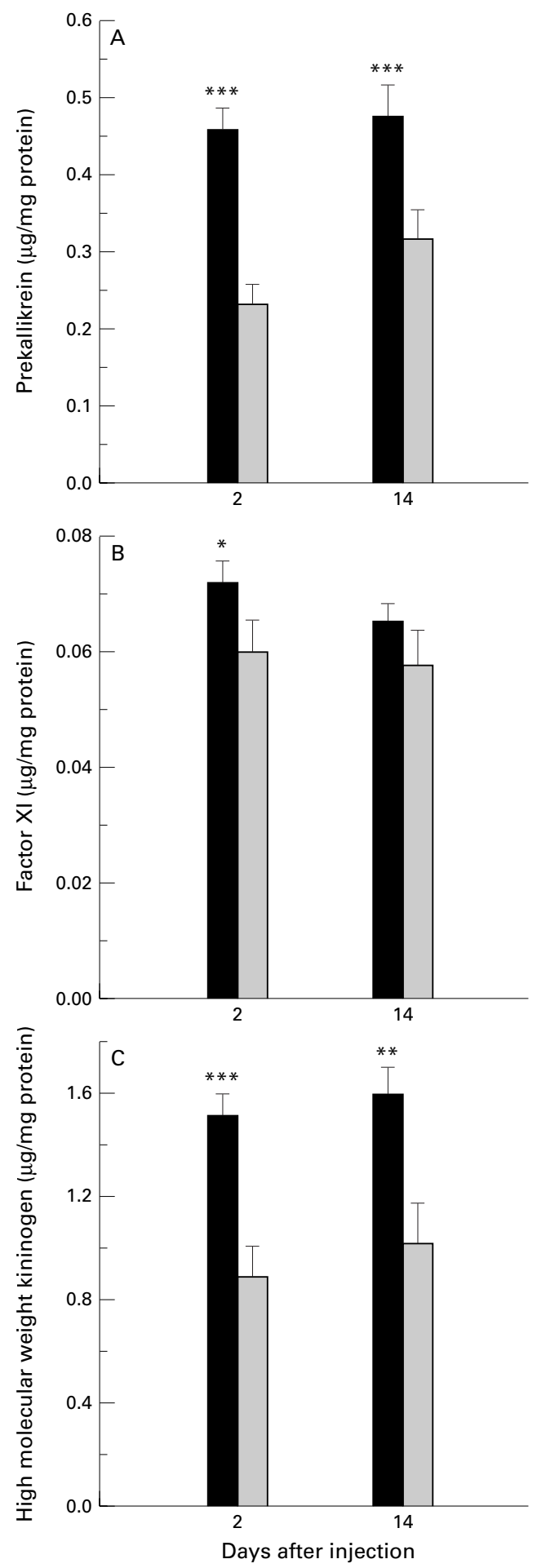

Figure 3 Functional assays of contact system proteins. (A) Prekallikrein; (B) factor XI; (C) high molecular weight kininogen. ${ }^{\star} p<0.05,{ }^{\star} p_{p}<0.01$, ${ }^{\star *} \star_{p}<0.001$. Solid bars indicate control groups; shaded bars indicate indomethacin treated groups.

used to evaluate differences between control and treated groups; $p$ values not greater than 0.05 were considered significant.

\section{Results}

INTESTINAL INFLAMMATION

Rats treated with two daily subcutaneous injections of indomethacin developed acute intestinal inflammation manifested grossly at two days by thickening of the bowel wall and mesentery, adhesions, and mesenteric haemorrhage. In addition, multiple small discrete mucosal ulcers on the mesenteric side of the small intestine were observed in the jejunum and ileum. Ulcers were evident from the serosed surface by focal thickening of the mesentery. Superficial caecal ulceration was present on the mucosal surface, but was not visible externally and was not quantified in this study. Mucosal blood was manifested by black luminal contents in the mid and distal small bowel, caecum, and colon; luminal contents were strongly Haemoccult positive. Histologically, the ulcers showed necrosis of the entire mucosa and severe serosal inflammation with neutrophils and macrophages as the predominant infiltrating cells (fig 1A). At 14 days, rats exhibited a more chronic inflammatory response with dramatically thickened, adherent, and hyperaemic mid small intestine (distal jejunum to proximal ileum) with contraction and thickening of the mesentery, and with "creeping" mesenteric fat on the serosal surface of the intestine (fig 2A). Deep, longitudinal, or stellate mucosal ulcers were uniformly present on the mesenteric border (fig 2B). No intestinal bleeding or caecal ulcerations were present. Histologically, ulcers and crypt abscesses in the mucosa and transmural inflammation with fibrosis, hyperplasia of smooth muscle, and massive thickening of the submucosa were present (fig 1B). The control rats injected with buffer had no gross or histological inflammatory changes and no ulcers.

Table 1 summarises the intestinal gross, histological, and biochemical findings at days 2 and 14 following two daily subcutaneous injections of indomethacin or buffer. The mean blinded gross gut score was most pronounced in rats with chronic inflammation due to notable intestinal wall thickening and adhesions, whereas the number of intestinal ulcers was highest in rats during acute inflammation. The percentage of surface area ulcerated was, however, larger at the chronic time point due to the longitudinal nature of ulcers at 14 days. These ulcers frequently extended for $5 \mathrm{~cm}$ (fig 1B). The blinded histological inflammatory score was notably increased over controls in both the acute and chronic phases. Intestinal IL-1 $\beta$ concentration, an index of macrophage activation, provided biochemical confirmation of the gross and histological observations in both phases of inflammation.

\section{SYSTEMIC INFLAMMATION}

Table 2 summarises the extraintestinal manifestations in rats treated with indomethacin compared with controls. Two days after indomethacin injection, rats had a significant decrease in total body weight and significant increases in absolute and normalised liver and spleen weights. In addition, there was a statistically significant decrease in the haematocrit of indomethacin injected rats, in part due to intestinal bleeding. The chronic phase of inflammation in indomethacin treated rats was characterised by a significant decrease in total body weight, a notable increase in spleen and 


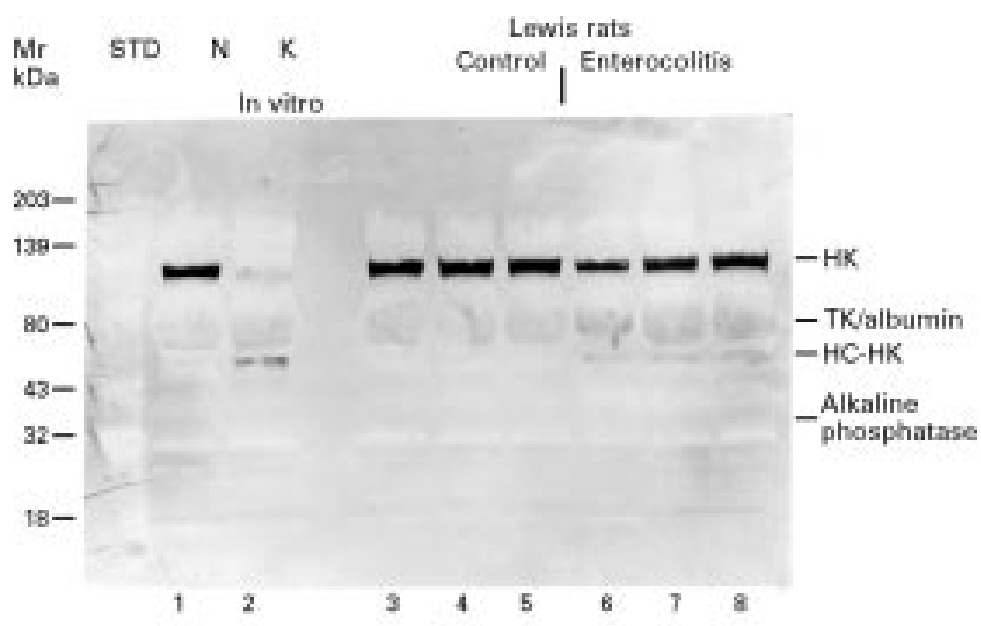

Figure 4 High molecular weight kininogen cleavage in Lewis rats treated with indomethacin shown by western blotting using anti-high molecular weight kininogen antibodies. Lane 1 shows pooled non-activated normal rat plasma (N), and lane 2 pooled rat plasma following exposure to kaolin $(K)$. Lanes 3-5 represent the plasma samples of three control rats, while lanes 6-8 are plasma samples of rats 14 days after treatment with indomethacin. The $120 \mathrm{kDa}$ band represents HK and is visualised across lanes 1 and 3-8, but is absent in lane 2. The broad band localised at about $68 \mathrm{kDa}$ across all lanes indicates cross reacting $T$ kininogen (TK) and albumin. The band situated between albumin and the $43 \mathrm{kDa}$ standard, visualised on lane 2 and lanes 6-8, but not on lane 1 and lanes 3-5, represents the heavy chain of high molecular weight kininogen (HC-HK, $62 \mathrm{kDa}$ ). The delicate band situated just above $32 \mathrm{kDa}$, standard across all lanes, represents a non-specific reaction with alkaline phosphatase that hydrolyses the BCIP/NBT substrate used to develop the colour.

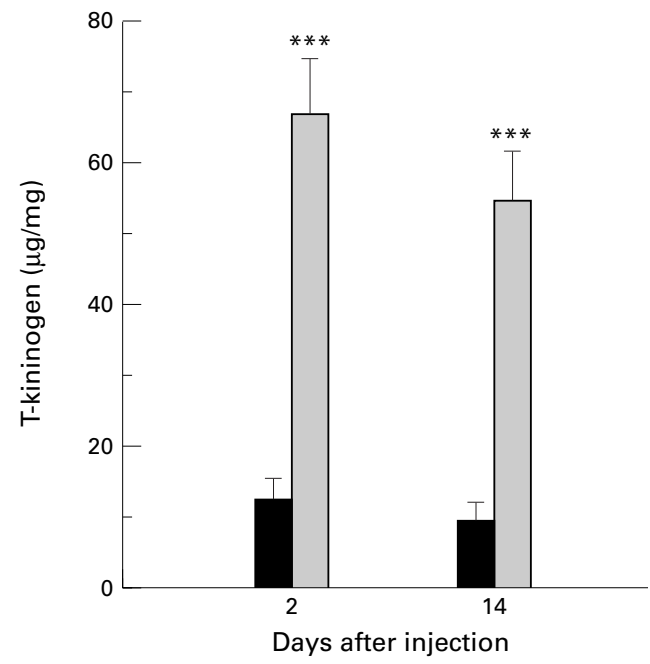

Figure 5 Plasma T kininogen levels during acute phase (two days) and chronic phase (14 days) of inflammation after indomethacin injection (mean (SEM)). T kininogen levels are expressed as $\mu \mathrm{g} / \mathrm{mg}$ plasma protein. ${ }^{\star \star \star} p<0.001$. Solid bars, buffer control rats; shaded bars, rats treated with indomethacin.

4, an $\mathrm{HK}$ band $(\mathrm{Mr}=120 \mathrm{kDa})$ is visualised in lane 1 which represents normal pooled rat plasma, which was not activated. In lane 2 , the band at $120 \mathrm{kDa}$ is virtually absent, which indicates $\mathrm{HK}$ cleavage. Although the protein applied to the gel is identical, the control rat plasma samples on lanes 3-5 have a higher concentration of $\mathrm{HK}$ than plasma samples from indomethacin treated chronically diseased rats on lanes $6-8$, suggesting cleavage of $\mathrm{HK}$ in the latter group. The bands indicating the HK cleavage product, heavy chain (HC$\mathrm{HK})(\mathrm{Mr}=62 \mathrm{kDa})$ are visualised in plasma activated in vitro (lane 2) and in rats with inflammation (lanes 6-8), but not in control plasma or in plasma of control rats (lanes 3-5). A similar HK cleavage pattern was observed in indomethacin treated rat plasma in the acute phase of inflammation (not shown). Thus, this assay indicates that in vivo cleavage of $\mathrm{HK}$ occurs in rats with indomethacin induced inflammation.

T KININOGEN LEVELS IN RAT PLASMA

$\mathrm{T}$ kininogen specific levels (as $\mu \mathrm{g} \mathrm{T}$ kininogen per mg total plasma protein) were significantly increased in indomethacin treated rats compared with controls rats at day 2 and remained significantly higher than controls at day 14 , as shown in fig 5 . Thus, $\mathrm{T}$ kininogen, a major acute phase protein in the rat, is elevated in both phases of inflammation. significantly decreased at two days and remained significantly lower at 14 days in indomethacin treated rats compared with buffer treated rats (fig 3C).

To test further whether the kallikrein-kinin system was activated in indomethacin treated rats, representative plasma samples were evaluated for the molecular weight distribution of HK by western blotting. To define the changes which might be expected, the contact system in pooled normal Lewis rat plasma was activated in vitro with kaolin and the pattern compared with that in unactivated plasma. As seen in fig
IMMUNOHISTOCHEMICAL LOCALISATION OF B2 RECEPTORS IN RAT INTESTINE

The B2 receptor was visualised in normal as well as in inflammatory rat intestine. Figures $6 \mathrm{~A}-\mathrm{C}$ illustrate the B2 receptor in normal intestine. Some epithelial cells in the villi display weak, focal immunoreactivities (fig $6 \mathrm{~A})$. At higher magnification $(\times 400)$ of a villus, focal staining is shown in cytoplasm of the epithelial cells in the crypt (fig 6B). Immunostaining is also present in the smooth muscle cells of 


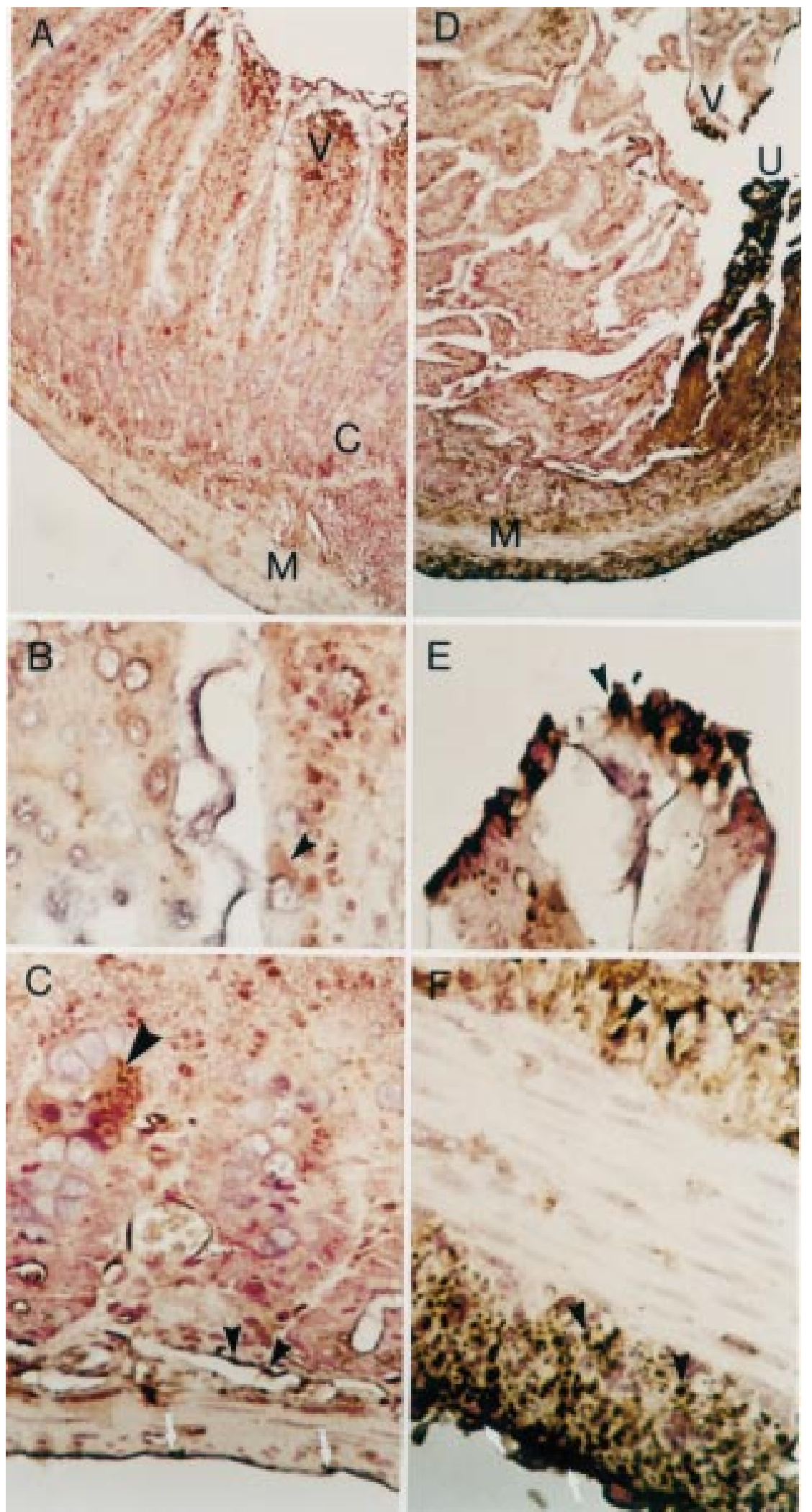

Figure 6 Immunolocalisation of the kinin B2 receptor in rat intestine on day 2. A-C: Rat normal control jejunum (buffer treated). (A) Some focal staining positive for B2 receptor in the villi-V, occasionally in the muscularis mucosa below the crypts $-C$, in the muscular layer- $M$, and in the serosa. Original magnification $\times 100$. (B) Intestinal villi. Focal weak immunostaining in the surface of occasional epithelial cells and in cytoplasm (arrow). Original magnification $\times 400$. $(C)$ Some focal immunostaining, cluster of epithelial cells in crypts (large arrow), in the muscular layers (small solid arrows), and in serosal surface (white arrows). Original magnification $\times 400 . D-F$ : Rat inflamed intestine (day 2 after injection of indomethacin). (D) Focal immunostaining in the villi-V, especially near the area of ulceration - U, in the internal and external muscular layer $-M$, and in the serosa. Original magnification $\times 100$. (E) Villus near area of ulceration showing strong staining in the epithelial, probably absorptive cells (arrow). Original magnification $\times 400$. (F) Prominent immunostaining in the smooth muscle cells of the muscularis mucosa (solid arrows) and in the external muscular laver (solid arrows). On the serosal surface, staining is also present (white arrows). Original magnification $\times 400$. 
the muscular layer as well as on the serosal surface (fig 6A,C). Note also weak nuclear staining.

Figures $6 \mathrm{D}-\mathrm{F}$ show specific staining of B2 receptors in inflamed rat intestine. Strong immunostaining is present in some villi bordering areas of the ulceration (fig 6D). Higher magnification of the villus $(\times 400)$ shows strong specific staining in the epithelial cells that show histological features of absorptive cells (fig 6E). Prominent immunostaining appears in the smooth muscle cells of the muscularis mucosa and in the internal and external layers of the muscularis as well as on the serosal surface (fig $6 \mathrm{D}, \mathrm{F})$. The intestinal sections treated with non-immune serum (rabbit IgG) instead of anti-B2 receptor antibodies were always unstained (data not shown).

In general, more prominent immunostaining in the epithelial cells of villi, smooth muscle cells, and serosal surface was found in the sections of inflamed intestine compared with normal intestine.

\section{Discussion}

The indomethacin induced model of enteropathy was described initially more than 25 years ago. ${ }^{29}$ This agent, administered subcutaneously or orally, has been found to produce small intestinal and colonic ulcers in rodents in a dose dependent fashion. Most early reports evaluated only acute intestinal injury, because investigators used doses greater than $10 \mathrm{mg} / \mathrm{kg}$, which were lethal, leading to intestinal perforation in two to four days. ${ }^{30} 31$ More recently, Sartor et $a l^{16}$ modified this model using two sublethal daily doses of indomethacin $(7.5 \mathrm{mg} / \mathrm{kg})$ to evaluate genetic susceptibility in inbred rats. ${ }^{16}$ This model induces acute intestinal injury (peak two days), which evolves into chronic intestinal inflammation lasting up to 11 weeks in susceptible Lewis rats with associated extraintestinal manifestations. To evaluate the gross gut score, we used the same criteria as in the PG-PS induced intestinal inflammatory model. However, in contrast to intestinal inflammation triggered by PG-PS, in which mucosal ulceration was quite rare, the indomethacin model is characterised by large numbers of ulcers in the mid small bowel. Chronic inflammation displays gross and histological features which in many aspects mimic Crohn's enteritis, such as bowel wall thickening with linear ulcers, transmural inflammation with fibrosis, and "creeping fat" in the mesentery. In addition, similar to Crohn's disease, ${ }^{32}$ indomethacin induced enterocolitis is characterised by increased intestinal permeability. ${ }^{33}{ }^{34}$ Finally, this model exhibits a genetic component: chronic inflammation develops in genetically susceptible Lewis rats; resistant Fisher rats display only mild, transient injury $^{16}$; and Sprague-Dawley rats develop intermediate responses. ${ }^{34}$

The mechanisms of intestinal injury initiated by indomethacin have not been entirely defined. In the present study we measured functional levels of the plasma contact proteins to ascertain whether there was associated activation of the kallikrein-kinin system. The decrease in plasma precursor proteins PK, FXI, and HK indicates conversion of these proteins to active enzymes (kallikrein and factor XIa) and active cofactor ( $\mathrm{HKa}$ ). Activation of the contact system is even more striking in the acute phase than in the acute PG-PS induced model, as the decrease in PK and HK is $50 \%$ and $35 \%$, respectively, in rats treated with indomethacin compared with controls, as opposed to a $20 \%$ and $30 \%$ decrease in PK and HK activities, respectively, in the acute phase of PG-PS induced enterocolitis. ${ }^{3}$ The specific plasma levels of each protein were calculated; thus, the moderate decrease in total plasma protein concentration in indomethacin treated rats makes significant depletion of contact proteins by intestinal leakage and/or decreased liver synthesis much less likely. Furthermore, increased plasma levels of the acute phase protein, $\mathrm{T}$ kininogen, confirms adequate hepatic synthetic function in indomethacin treated rats. In addition, our demonstration, for the first time, of $\mathrm{HK}$ cleavage in diseased rats, but not in control rats, strongly supports continued activation of the contact system.

$\mathrm{HK}$ cleavage to $\mathrm{HKa}$ by plasma kallikrein results in release of bradykinin, which directly binds to and stimulates B2 receptors. The present study visualises for the first time the B2 receptors in the intestine at the cellular level, which provides a structural basis for the kinin function. This finding agrees with the involvement of bradykinin in acute inflammation. B2 receptors were shown in epithelial cells, smooth muscle cells and, interestingly, also on the serosal surface. Furthermore, more prominent specific staining in inflamed tissue compared with normal controls suggests that B2 receptor expression increases during inflammation. In fact, recent in vivo data showed that acute arthritis induced in rats by PG-PS is mediated in part by bradykinin through the $\mathrm{B} 2$ receptor. ${ }^{35}$ The regulation of $\mathrm{B} 2$ receptor expression during chronic inflammation will require future study using quantitative methods. B2 receptors are not apparently up regulated during chronic inflammation, during which $\mathrm{B} 1$ receptors play a major role. ${ }^{10}$ Therefore, we did not study the constitutively expressed B2 receptors at 14 days. Unfortunately, antibodies against the inducible B1 receptor in rats are still not available. Bradykinin itself cannot be measured accurately because of its short (less than 30 seconds) halflife in vivo and the difficulty in preventing in vitro release during blood collection.

The contact activation in this model may reflect the pathophysiological response to intestinal tissue injury. The possible mechanisms are not clear, as potential factors such as endothelial perturbation, leucocyte stimulation, or the presence of bacterial proteases in the circulation have not been completely defined in indomethacin initiated intestinal inflammation. However, in the present study we show the impressive increase in plasma $T$ kininogen levels in indomethacin treated rats, which reflects an acute phase reaction. ${ }^{36}$ The synthesis of acute phase proteins in the liver is known to be triggered by interleukin 6 . As 
interleukin 6 expression requires interleukin 1 (IL-1), a key proinflammatory cytokine, this acute phase response in indomethacin treated rats suggests the stimulation of monocytes and/or endothelial cells, which leads to IL-1 release. Our results document significant increases in intestinal IL- $1 \beta$ in acute and chronic phases of inflammation. A pathogenic role of IL-1 is further suggested by the preliminary results of Sartor et $a l,^{37}$ who reported that recombinant IL-1 receptor antagonist diminished acute and chronic inflammation induced by indomethacin in Lewis rats. Furthermore, IL-6 is known to mediate anaemia in chronic diseases, ${ }^{38}$ which may explain the sustained fall in haematocrit in the chronic phase of our model despite the lack of mucosal blood loss. Anaemia in the acute phase is probably caused in part by moderate intestinal bleeding, which is observed more frequently in the mid small intestine than in the stomach in this model.

Several factors have been postulated to initiate and perpetuate an increase in intestinal permeability and ulcerations, the most characteristic morphological changes in indomethacin initiated experimental enteropathy. ${ }^{32}$ Most attention has been paid to alterations of arachidonic acid metabolism. In human and experimental IBD, thromboxanes and leukotrienes are proinflammatory, whereas prostaglandins are protective. ${ }^{2}$ Previous studies ${ }^{39} 40$ indicated that inhibition of prostaglandins can lead to epithelial damage in the gastrointestinal tract. However, other metabolic pathways of arachidonic acid are also important because indomethacin induced intestinal lesions were prevented or treated by thromboxane synthetase inhibitors ${ }^{34}$ as well as inhibitors of 5-lipooxygenase. ${ }^{41}$ The lipooxygenase pathway product, leukotriene $\mathrm{B} 4$, is thought to be derived predominantly from neutrophils in the intestine.

Neutrophil accumulation, reflected by histological score and increased myeloperoxidase (MPO) concentration, is evident in enterocolitis induced by indomethacin. ${ }^{1634}$ Neutrophilic infiltration was a prominent feature of both acute and chronic phases of indomethacin induced small intestinal injury in Lewis rats. In this model there is a six- to eightfold increase in leucocyte endothelial cell adherence and emigration. ${ }^{42}$ Neutrophil induced tissue injury is thought to be predominantly mediated by extracellular secretion of lysosomal enzymes and superoxide. ${ }^{43}$ As kallikrein is a known chemoattractant for neutrophils and stimulates elastase release, ${ }^{78}$ activation of the kallikreinkinin system may be one of the stimuli of neutrophil related injury. In our PG-PS induced enterocolitis model, we showed that a specific kallikrein inhibitor decreased intestinal MPO activity, ${ }^{5}$ which strongly indicates a pathogenic relation between kallikrein-kinin activation and intestinal neutrophil recruitment.

The current experimental model is in many aspects different from PG-PS induced enterocolitis, including the fact that the triggering agent is not an exogenous bacterial polymer. However, previous investigations have shown that resident luminal bacteria strongly contrib- ute to the inflammatory response in rats treated by indomethacin. Small intestinal inflammation induced by indomethacin has been shown to be inhibited or treated by broad spectrum antibiotics, ${ }^{30}{ }^{34}$ whereas acute arthritis is attenuated and chronic inflammation does not occur in germ free (sterile) Lewis rats. ${ }^{44}$ The results of Yamada and coworkers ${ }^{34}$ indicated that the chronic phase, but not the acute phase of indomethacin induced enterocolitis, is attenuated by metronidazole, and hence may be mediated by luminal anaerobic bacteria. Furthermore, these authors showed enhanced translocation of intestinal bacteria to mesenteric lymph nodes after indomethacin exposure. However, in the current model, in which acute inflammation evolves into chronic mid small bowel ulceration, we show activation of the kallikrein-kinin system in both acute and chronic phases. It is possible that ubiquitous intestinal bacterial constituents, as well as exogenous bacterial products such as PG-PS and LPS, are responsible for activation of the contact system, in keeping with observations in experimental and clinical septic shock. ${ }^{13-15}$

The biochemical and morphological changes observed in our experimental animal model may have relevance to human enteropathies, especially IBD. Chronic administration of certain non-steroidal anti-inflammatory drugs (NSAIDs) such as indomethacin to humans increased small intestinal permeability, ${ }^{45}$ which has long been recognised as an early pathological change in Crohn's disease. ${ }^{133}$ Furthermore, Bjarnason and coworkers ${ }^{46}$ have shown that NSAIDs cause small intestinal inflammation, in some cases with strictures, in two thirds of patients during long term treatment. These drugs also emerged as an important factor in the relapse of patients with ulcerative colitis. ${ }^{47}$ Recently, we have shown that activation of the kallikrein-kinin system occurs in patients with active ulcerative colitis, ${ }^{48}$ and that acute ${ }^{5}$ and chronic $^{12}$ PG-PS induced enterocolitis in the rat is inhibited by a specific kallikrein inhibitor. Whether kallikrein-kinin system activation participates in human enteropathy caused or aggravated by indomethacin remains to be investigated. Taken together, these results show that kallikrein-kinin system activation occurs in experimental and human intestinal inflammation of diverse aetiologies, suggesting that the contact system is an important mediator of enterocolitis and could provide a target for therapeutic intervention.

We are appreciative of the careful manuscript preparation by Rita Stewart and the technical assistance of Julie Mitchell of the Immunoassay Core Facility of the Center for Gastrointestinal Biology and Disease, University of North Carolina. We thank Dr Werner Müller-Esterl for antirat B2 antibodies. This work was supported by grants from NIH, DK43735 (RWC), DK40249 (RBS), and DK34987 (RBS).

1 Sartor RB. Current concepts of the etiology and pathogenClin North Am 1995;24:475-508.

2 Elson CO, Sartor RB, Tennyson GS, et al. Experimental models of inflammatory bowel disease. Gastroenterology 1995;109:1344-67.

3 Sartor RB, DeLa Cadena RA, Green KD, et al. Selective kallikrein-kinin system activation in inbred rats differentially susceptible to granulomatous enterocolitis. Gastroenterology 1996;110:1467-81. 
4 Schwab JH. Phlogistic properties of peptidoglycanpolysaccharide polymers from cell walls of pathogenic and 1993;61:4535-9.

5 Stadnicki A, DeLa Cadena RA, Sartor RB, et al. Selective plasma kallikrein inhibitor attenuates acute intestinal inflammation in Lewis rat. Dig Dis Sci 1996;41:912-20.

6 DeLa Cadena RA, Wachtfogel YT, et al. Contact activation pathway: inflammation and coagulation. In: Colman RW, Hirsh J, Marder VJ, et al, eds. Hemostasis and thrombosis. basic principles and clinical practice. Philadelphia: JB Lippincott, 1994:219-40.

7 Schapira M, Despland E, Scott CF, et al. Purified human plasma kallikrein aggregates human blood neutrophils. $\mathcal{f}$ Clin Invest 1982;69:1199-202.

8 Wachtfogel YT, Kucich U, James HL, et al. Human plasma kallikrein releases neutrophil elastase during blood coagulation. F Clin Invest 1983;72:1672-7.

9 Zimmerli W, Huber I, Bouma BN, et al. Purified human plasma kallikrein does not stimulate but primes neutrophils plasma kallikrein does not stimulate but primes neutrophils
for superoxide production. Thromb Haemost 1989;62: for super.

10 Bhoola KD, Figueroa CD, Worthy K. Bioregulation of kinins, kallikrein, kininogens and kinases. Pharmacol Rev 1992;44:1-80

11 Gaginella TS, Kachur JF. Kinins as mediators of intestinal secretion. Am f Physiol 1989;256:G1-15.

12 Stadnicki A, Sartor RB, Janardham R, et al. Specific inhibition of plasma kallikrein modulates chronic granulomatous intestinal and systemic inflammation in genetically susceptible rats. FASEB f 1998;12:325-33.

13 Colman RW, Flores DN, De La Cadena RA, et al. Recombinant alpha 1-antitrypsin Pittsburgh attenuates experimental Gram-negative septicemia. Am $\mathcal{F}$ Pathol 1988; 130:418-26.

14 Pixley RA, DeLa Cadena RA, Page JD, et al. The contact system contributes to hypotension but not disseminated intravascular coagulation in lethal bacteremia: in vivo use of a monoclonal anti-factor XII antibody to block contact a monoclonal anti-factor XII antibody to block

15 Pixley RA, Zellis S, Bankes P, et al. Prognostic value of assessing contact system activation and factor $\mathrm{V}$ in systemic inflammatory response syndrome. Crit Care Med 1995;23: $41-51$

16 Sartor RB, Bender DE, Holt LC. Susceptibility of inbred rat strains to intestinal inflammation induced by indomethacin [abstract]. Gastroenterology 1992;102:A690.

17 Schreiber GA, Tsykin A, Aldred AR, et al. The acute phase response in the rodent. Ann N Y Acad Sci 1989;557:61-86.

18 Rath HC, Herforth HH, Ikeda JS, et al. Normal luminal bacteria, especially Bacteroides species, mediate chronic colitis, gastritis, and arthritis in HLA-B27/human beta2 microglobulin transgenic rats. 7 Clin Invest 1996;98:94553.

19 DeLa Cadena RA, Scott CF, Colman RW. Evaluation of a microassay for human plasma prekallikrein. $\mathcal{F} \mathrm{Lab}$ Clin Med 1987;109:601-7.

20 Scott CF, Colman RW. A simple and accurate microplate assay for the determination of factor XI in plasma. $\mathcal{F} \mathrm{Lab}$ assay for the determination

21 Colman RW, Bagdasarian A, Talamo RC, et al. Williams trait. Human kininogen deficiency with diminished levels of plasminogen proactivator and prekallikrein associated with abnormalities of the Hageman factor-dependent pathways. F Clin Invest 1975;56:1650-62.

22 Proctor RR, Rapaport SI. The partial thromboplastin time with kaolin: a simple screening test for first stage plasma clotting factor deficiencies. Am f Clin Pathol 1961;36:21219.

23 Bradford MM. A rapid and sensitive method for the quantitation of microgram quantities of protein utilizing the principle of protein-dye binding. Anal Biochem 1976;72:24854 .

24 Hjelm H, Hjelm K, Sjoquist J. Protein A from Staphylococcus aureus. Its isolation by affinity chromatography and its
use as an immunosorbent for isolation of immunoglobuuse as an immunosorbent for
lins. FEBS Lett 1972;28:73-6.

25 Hock J, Vogel R, Linke RP, et al. High molecular weight kininogen-binding site of prekallikrein probed by monoclonal antibodies. f Biol Chem 1990;265:12005-11.
26 Adam A, Damas J, Calay G, et al. Quantification of rat T-kininogen using immunological methods. Application to inflammatory processes. Biochem Pharmacol 1989;38: 1569-75.

27 Figueroa CD, Gonzalez CB, Grigoriev S, et al. Probing for the bradykinin B2 receptor in rat kidney by anti-peptide and anti-ligand antibodies. F Histochem Cytochem 1995;43: $137-48$.

28 Tallarida RJ, Murray RG. Manual of pharmacologic calculations with computer programs. New York: Springer-Verlag, 1987:121-20.

29 Kent TH, Cardelli RM, Stamler FW. Small intestinal ulcers and intestinal flora in rats given indomethacin. Am $\mathcal{F}$ Pathol 1969;54:237-49.

30 Robert A. An intestinal disease produced experimentally by a prostaglandin deficiency. Gastroenterology 1975;69:10457 .

31 Fang WF, Broughton A, Jacobson ED. Indomethacininduced intestinal inflammation. Am f Dig Dis 1977;22: 749-60.

32 Hollander D. The intestinal permeability barrier. A hypothesis as to its regulation and involvement in Crohn's disease. Scand f Gastroenterol 1992;27:721-6.

33 Banerjee AK, Peters TJ. Experimental non-steroidal antiinflammatory drug-induced enteropathy in the rat: similarities to inflammatory bowel disease and effect of thromboxane synthetase inhibitors. Gut 1990;31:1358-64.

34 Yamada T, Deitch E, Specian RD, et al. Mechanisms of acute and chronic intestinal inflammation induced by indomethacin. Inflammation 1993;17:641-62.

35 Blais C Jr, Couture R, Drapeau G, et al. Endogenous kinins are involved in the pathogenesis of peptidoglycan-induced arthritis in the Lewis rat. Arthritis Rheum 1997;40:132733.

36 Schreiber G, Tsykin A, Aldred AR, et al. The acute phase response in the rodent. Ann N Y Acad Sci 1989;557:61-85.

37 Sartor RB, Holt L, Bender DE, et al. Prevention and treatment of experimental enterocolitis with a recombinant interleukin-1 receptor antagonist [abstract]. Gastroenterology 1991;100:A613.

38 Means RT, Krantz SB. Progress in understanding the pathogenesis of the anemia of chronic disease. Blood 1992; 80:1639-47.

39 Whittle BJ. Temporal relationship between cyclooxygenase inhibition, as measured by prostacyclin biosynthesis, and the gastrointestinal damage induced by indomethacin in the gastrointestinal damage induced
the rat. Gastroenterology 1981;80:94-8.

40 Redfern JS, Blair AJ, Lee E, et al. Gastrointestinal ulcer formation in rabbits immunized with prostaglandin E2. Gastroenterology 1987;93:744-52.

41 Miura S, Suematsu M, Tanaka S, et al. Microcirculatory disturbance in indomethacin-induced intestinal ulcer. $A m \mathcal{F}$ Physiol 1991;261:G213-19.

42 Pennica D, Holmes WE, Kohr WJ, et al. Cloning and expression of human tissue-type plasminogen activator cDNA in E. coli. Nature 1983;301:214-21.

43 Conner EM, Brand SJ, Davis JM, et al. Role of reactive metabolites of oxygen and nitrogen in inflammatory bowel disease: toxins, mediators, and modulators of gene expression. Inflammatory Bowel Disease 1996;2:133-47.

44 Sartor RB, Bender DE, Guenther R, et al. Absolute requirement for ubiquitous luminal bacteria in the pathogenesis of chronic intestinal inflammation [abstract]. Gastroenterology 1994:106:A747.

45 Banerjee AK. Enteropathy induced by non-steroidal antiinflammatory drugs. $B M \mathcal{F}$ 1989;298:1539-40.

46 Bjarnason I, Zanelli G, Smith T, et al. Nonsteroidal antiinflammatory drug-induced intestinal inflammation in humans. Gastroenterology 1987;93:480-9.

47 Kaufmann HJ, Taubin HL. Nonsteroidal anti-inflammatory drugs activate quiescent inflammatory bowel disease. Ann Intern Med 1987;107:513-16.

48 Stadnicki A, Gonciarz M, Niewiarowski TJ, et al. Activation of plasma contact and coagulation systems and neutrophils in the active phase of ulcerative colitis. Dig Dis Sci 1997;42: 2356-66. 